\title{
Neisseria weaveri sp. nov. (formerly CDC Group M-5), from Dog Bite Wounds of Humans
}

\author{
B. HOLMES, ${ }^{1 *}$ M. COSTAS, ${ }^{1}$ S. L. W. ON, ${ }^{1}$ P. VANDAMME,${ }^{2,3}$ E. FALSEN,${ }^{4}$ AND K. KERSTERS ${ }^{2}$ \\ Epidemiological Identification and Typing Laboratory, National Collection of Type Cultures, Central Public \\ Health Laboratory, London NW9 5HT, United Kingdom ${ }^{1}$; Laboratorium voor Microbiologie, University of \\ Ghent, B-9000 Ghent, ${ }^{2}$ and Department of Microbiology, University Hospital, Antwerp, ${ }^{3}$ Belgium; and Culture \\ Collection, Department of Clinical Bacteriology, University of Göteborg, S-413 46 Göteborg, Sweden ${ }^{4}$
}

\begin{abstract}
The taxonomic relationships of strains belonging to Centers for Disease Control group M-5 were examined. Previous studies of rRNA cistron similarities placed this organism on the Neisseriaceae rRNA branch of rRNA superfamily III; the closest neighbors included the genus Neisseria and groups EF-4a and EF-4b. The group M-5 strains were characterized by a range of phenotypic tests, and their $G+C$ contents and DNA-DNA relatedness levels were determined. In addition, a numerical taxonomic analysis of the whole-cell protein patterns (obtained by sodium dodecyl sulfate-polyacrylamide gel electrophoresis) of group M-5 and related taxa was performed. The strains studied included 45 group M-5 strains, the type strains of six Neisseria species or subspecies, three group EF-4a reference strains, and three group EF-4b reference strains plus the type strain of the phenotypically similar organism Oligella urethralis. Our results showed that the group M-5 strains were members of a homogeneous taxon distinct from phylogenetically closely related taxa. The genomic divergence as revealed by levels of rRNA cistron similarity and phenotypic characteristics indicate that group $\mathbf{M - 5}$ can be considered a new species of the genus Neisseria. We therefore propose the new species Neisseria weaveri, with NCTC 12742 (= CCUG $4007=$ ISL775/91 = LMG 5135) as the type strain. $N$. weaveri strains are strictly aerobic, gram-negative, nonmotile, rod-shaped organisms which are catalase and oxidase positive, nonsaccharolytic, and able to grow on MacConkey agar and do not reduce nitrate but generally reduce nitrite. The guanine-plus-cytosine contents of the DNAs of six representative strains were in the range from 50 to 51 mol\%. Almost all 45 group M-5 strains were originally isolated from human wounds following dog bites.
\end{abstract}

In 1974, Tatum et al. (24) described a number of $M o-$ raxella-like taxa, one of which they designated group $\mathrm{M}-5$. Of the 41 group M-5 cultures which these authors examined, 25 were obtained from infected wounds following dog bites, 4 were obtained from the respiratory tracts of dogs, and the remaining 12 were obtained from human wounds. In a subsequent review of Moraxella-like organisms submitted for identification to the Centers for Disease Control (CDC) in the period from 1953 to 1980,66 of 74 group M-5 isolates were from wounds, and 53 were from dog bites (13). The organism was found to be present in $18 \%$ of gingival scrapings from 50 dogs (23) and also proved to be present in the oral cavities of $12 \%$ of another group of 50 dogs (1). Despite its common occurrence in canine oral cavities, the incidence of group M-5 organisms in dog bite wounds is lower than might perhaps be expected; they were found in three noninfected dog bite wounds in 26 patients (12), 8 of 73 positive samples obtained from inflamed animal bites or scratches (5), and $4 \%$ of animal bite wounds (4). Although most strains have been reported from the United States $(1,4,12,13,23$, 24), other strains have been reported from France (5). Reports from the United Kingdom have been limited to one definite identification of a group $M-5$ strain from a finger wound following a dog bite (2) and a case of a strain resembling the group M-5 organism (21).

The cellular fatty acid compositions of various organisms isolated from dog bite wounds have been compared $(8,20)$; group M-5 strains differ from typical moraxellas but share certain characteristics with group EF-4 strains (8), as well as group M-6 strains (20). DNA-rRNA hybridization data

\footnotetext{
* Corresponding author.
}

showed that both group M-5 and group EF-4 belong in an emended family Neisseriaceae (22).

The purpose of this study was to examine the within-taxon homogeneity of group M-5 organisms and to show how this taxon is differentiated from its closest relatives (as well as the phenotypically similar organism Oligella urethralis) by $\mathrm{G}+\mathrm{C}$ content, DNA-DNA hybridization levels, phenotypic characteristics, and whole-cell protein patterns obtained by sodium dodecyl sulfate-polyacrylamide gel electrophoresis (SDS-PAGE). We propose a new species, Neisseria weaveri, with strain NCTC 12742 (= CCUG $4007=$ ISL775/91 = LMG 5135) as the type strain.

\section{MATERIALS AND METHODS}

Bacterial strains. A total of 45 CDC group M-5 strains were examined. The type strains of six Neisseria species or subspecies, three CDC group EF-4a reference strains, three CDC group EF-4b reference strains, and the type strain of $O$. urethralis were also included as reference organisms. All of the reference strains (except the $O$. urethralis strain, which is phenotypically very similar to CDC group M-5) were included because they are known to have a close phylogenetic relationship to $C D C$ group $M-5$. The 58 cultures which we used are listed in Table 1 along with their sources and clinical information, where appropriate.

Culture media and conventional biochemical tests. Strains were grown overnight at $37^{\circ} \mathrm{C}$ on $5 \%$ blood agar containing (per liter) $25 \mathrm{~g}$ of nutrient broth no. 2 (catalog no. CM67; Oxoid), $12 \mathrm{~g}$ of New Zealand agar, and $50 \mathrm{ml}$ of horse blood. All strains were characterized by performing 68 conventional biochemical tests, using methods described previously (17). In addition, production of gas from nitrite was recorded, and production of acid from glucose and sucrose 
TABLE 1. Sources of strains studied

\begin{tabular}{|c|c|c|c|c|}
\hline \multirow{2}{*}{ Taxon } & \multirow{2}{*}{$\begin{array}{l}\text { Refer- } \\
\text { ence } \\
\text { no. }\end{array}$} & \multirow{2}{*}{ Strain $^{a}$} & \multicolumn{2}{|c|}{ Source of isolation } \\
\hline & & & Clinical source & Geographical area (year) \\
\hline \multirow[t]{45}{*}{ N. weaveri sp. nov. } & 1 & CL187/86 & Human lower leg lesion, dog bite & Basildon, United Kingdom (1986) \\
\hline & 2 & CL123/87 & Human wound, dog bite & Exeter, United Kingdom (1987) \\
\hline & 3 & CL149/87 & Human wound, dog bite & Lincoln, United Kingdom (1987) \\
\hline & 4 & CL198/88 & Human wound, dog bite & Bangor, United Kingdom (1988) \\
\hline & 5 & CL202/88 & Human wound, dog bite & London, United Kingdom (1988) \\
\hline & 6 & CL13/89 & Human wound, dog bite & Watford, United Kingdom (1989) \\
\hline & 7 & CL30/89 & Infected human hand wound & London, United Kingdom (1989) \\
\hline & 8 & CL5/90 & Human wound, dog bite & London, United Kingdom (1990) \\
\hline & 9 & CL200/90 & Human wound, dog bite & Harrogate, United Kingdom (1990) \\
\hline & 10 & CL445/90 & Human wound, dog bite & High Wycombe, United Kingdom (1990) \\
\hline & 11 & ISL718/91 & Human sputum, diabetic patient & Davyhulme, United Kingdom (1991) \\
\hline & 12 & 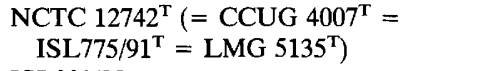 & Dog bite & Göteborg, Sweden (1974) \\
\hline & 13 & ISL231/92 & Human thumb wound, dog bite & London, United Kingdom (1992) \\
\hline & 14 & ISL310/92 & Human leg wound, dog bite & Salford, United Kingdom (1992) \\
\hline & 15 & $\begin{array}{l}\text { ISL387/92 (= CCUG } 9691=\text { CDC } \\
\text { B5522) }\end{array}$ & Human wound, dog bite & United States (1978) \\
\hline & 16 & ISL456/92 & Human hand wound, dog bite & Harrogate, United Kingdom (1992) \\
\hline & 17 & ISL459/92 & Human wound, dog bite & Harrogate, United Kingdom (1992) \\
\hline & 18 & ISL651/92 (= CCUG 4130B) & Human wound after dog bite & Göteborg, Sweden (1974) \\
\hline & 19 & ISL652/92 (= CCUG 9688) & Infected dog bite & Norway (1977) \\
\hline & 20 & ISL653/92 (= CCUG 9689) & Dog mouth & United States (1978) \\
\hline & 21 & $\begin{array}{l}\text { ISL654/92 (= CCUG } 9690=\text { CDC } \\
\text { B5107) }\end{array}$ & Dog bite & United States (1978) \\
\hline & 22 & ISL655/92 (= CCUG 9693) & Dog upper respiratory tract & Kansas (1978) \\
\hline & 23 & ISL656/92 (= CCUG 9694) & Dog upper respiratory tract & United States (1980) \\
\hline & 24 & ISL657/92 (= CCUG 13906) & Bite & Nice, France (1982) \\
\hline & 25 & ISL658/92 (= CCUG 13908) & Bite & Nice, France (1982) \\
\hline & 26 & ISL659/92 (= CCUG 13910A) & Unknown & Nice, France (1982) \\
\hline & 27 & ISL660/92 (= CCUG 18018) & Human wound, dog bite & Skövde, Sweden (1985) \\
\hline & 28 & ISL661/92 (= CCUG 21462) & Human wound, dog bite & Borås, Sweden (1987) \\
\hline & 29 & ISL662/92 (= CCUG 22467) & Human face wound, dog bite & Skövde, Sweden (1988) \\
\hline & 30 & ISL663/92 (= CCUG 22597) & Human wound, dog bite & Sundsvall, Sweden (1988) \\
\hline & 31 & ISL664/92 (= CCUG 24983) & Human wound, dog bite & Umeå, Sweden (1989) \\
\hline & 32 & ISL665/92 (= CCUG 25017) & Human wound, dog bite & Umeå, Sweden (1989) \\
\hline & 33 & ISL666/92 (= CCUG 25064) & Human wound, dog bite & Växjö, Sweden (1989) \\
\hline & 34 & ISL667/92 (= CCUG 25377) & Human hand wound, dog bite & Gävle, Sweden (1989) \\
\hline & 35 & ISL668/92 (= CCUG 25579) & Human wound, dog bite & Skövde, Sweden (1989) \\
\hline & 36 & ISL669/92 (= CCUG 25723) & Human wound, dog bite & Lidköping, Sweden (1989) \\
\hline & 37 & ISL670/92 (= CCUG 27417) & Human wound, dog bite & Skövde, Sweden (1990) \\
\hline & 38 & ISL671/92 (= CCUG 27634) & Human hand wound, bite & Göteborg, Sweden (1990) \\
\hline & 39 & ISL672/92 (= CCUG 28384) & Human & Borås, Sweden (1991) \\
\hline & 40 & ISL673/92 (= CCUG 28485) & Human hand wound, dog bite & Skövde, Sweden (1991) \\
\hline & 41 & ISL674/92 (= CCUG 28573) & Human hand wound, dog bite & Huddinge, Sweden (1991) \\
\hline & 42 & ISL675/92 (= CCUG 28753) & Human wound, dog bite & Danderyd, Sweden (1991) \\
\hline & 43 & ISL678/92 (= CCUG 19865) & Human wound, dog bite & Växjö, Sweden (1986) \\
\hline & 44 & ISL679/92 (= CCUG 13910B) & Human wound, dog bite & Nice, France (1982) \\
\hline & 45 & ISL680/92 (= CCUG 30381) & Human wound, dog bite & Danderyd, Sweden (1992) \\
\hline N. animalis & 46 & NCTC $10212^{\mathrm{T}}$ & Guinea pig & Hamburg, Germany \\
\hline N. canis & 47 & NCTC $10296^{\mathbf{T}}\left(=\right.$ ATCC $\left.14687^{\mathrm{T}}\right)$ & Dog oral mucosa & Hamburg, Germany \\
\hline N. denitrificans & 48 & NCTC $10295^{\mathrm{T}}\left(=\right.$ ATCC $\left.14686^{\mathrm{T}}\right)$ & Rabbit oral mucosa & Hamburg, Germany \\
\hline $\begin{array}{l}\text { N. elongata subsp. } \\
\text { elongata }\end{array}$ & 49 & NCTC $10660^{\mathrm{T}}\left(=\right.$ ATCC $\left.25295^{\mathrm{T}}\right)$ & Pharynx, healthy adult & Oslo, Norway \\
\hline $\begin{array}{l}\text { N. elongata subsp. } \\
\text { glycolytica }\end{array}$ & 50 & NCTC $11050^{\mathrm{T}}\left(=\right.$ ATCC $\left.29315^{\mathrm{T}}\right)$ & Throat swab & Oslo, Norway \\
\hline N. meningitidis & 51 & $\operatorname{NCTC} 10025^{\mathrm{T}}\left(=\operatorname{ATCC} 13077^{\mathrm{T}}\right)$ & Cerebrospinal fluid & Chicago, Ill. \\
\hline O. urethralis & 52 & CCUG $13463^{\mathrm{T}}\left(=\right.$ ATCC $\left.17960^{\mathrm{T}}\right)$ & Human ear & United States \\
\hline \multirow[t]{3}{*}{ Group EF-4a } & 53 & NCTC $12226(=$ CL480/77) & Human wound, dog bite & London, United Kingdom \\
\hline & 54 & $\begin{array}{l}\text { NCTC } 12227(=\text { CL643/80 = CIP } \\
268.80)\end{array}$ & Abscess following dog bite & Montreuil, France \\
\hline & 55 & $\begin{array}{l}\text { NCTC } 12228(=\text { CL191/78 = ATCC } \\
29858=\text { CDC D8251) }\end{array}$ & Thumb wound & Wisconsin \\
\hline \multirow[t]{3}{*}{ Group EF-4b } & 56 & $\begin{array}{l}\text { NCTC } 12230(=\text { CL194/78 = ATCC } \\
29859=\text { CDC D5986 })\end{array}$ & Human wound, dog bite & Hawaii \\
\hline & 57 & NCTC $12229(=$ CL641/80 = CIP 784-78) & Human wound, dog bite & Paris, France \\
\hline & 58 & NCTC 12231 (= CL724/80 = CDC C669) & Human vagina & Canada \\
\hline
\end{tabular}

${ }^{a}$ ATCC, American Type Culture Collection, Rockville, Md.; CDC, Centers for Disease Control, Atlanta, Ga.; CCUG, Culture Collection of the University of Göteborg, Göteborg, Sweden; CIP, Collection de l'Institut Pasteur, Paris, France; LMG, Culture Collection of the Laboratorium voor Microbiologie, Universiteit Gent, Ghent, Belgium; NCTC, National Collection of Type Cultures, Central Public Health Laboratory, London, United Kingdom. Strain designations beginning with CL or ISL are designations used by the National Collection of Type Cultures Identification Services Laboratory. 

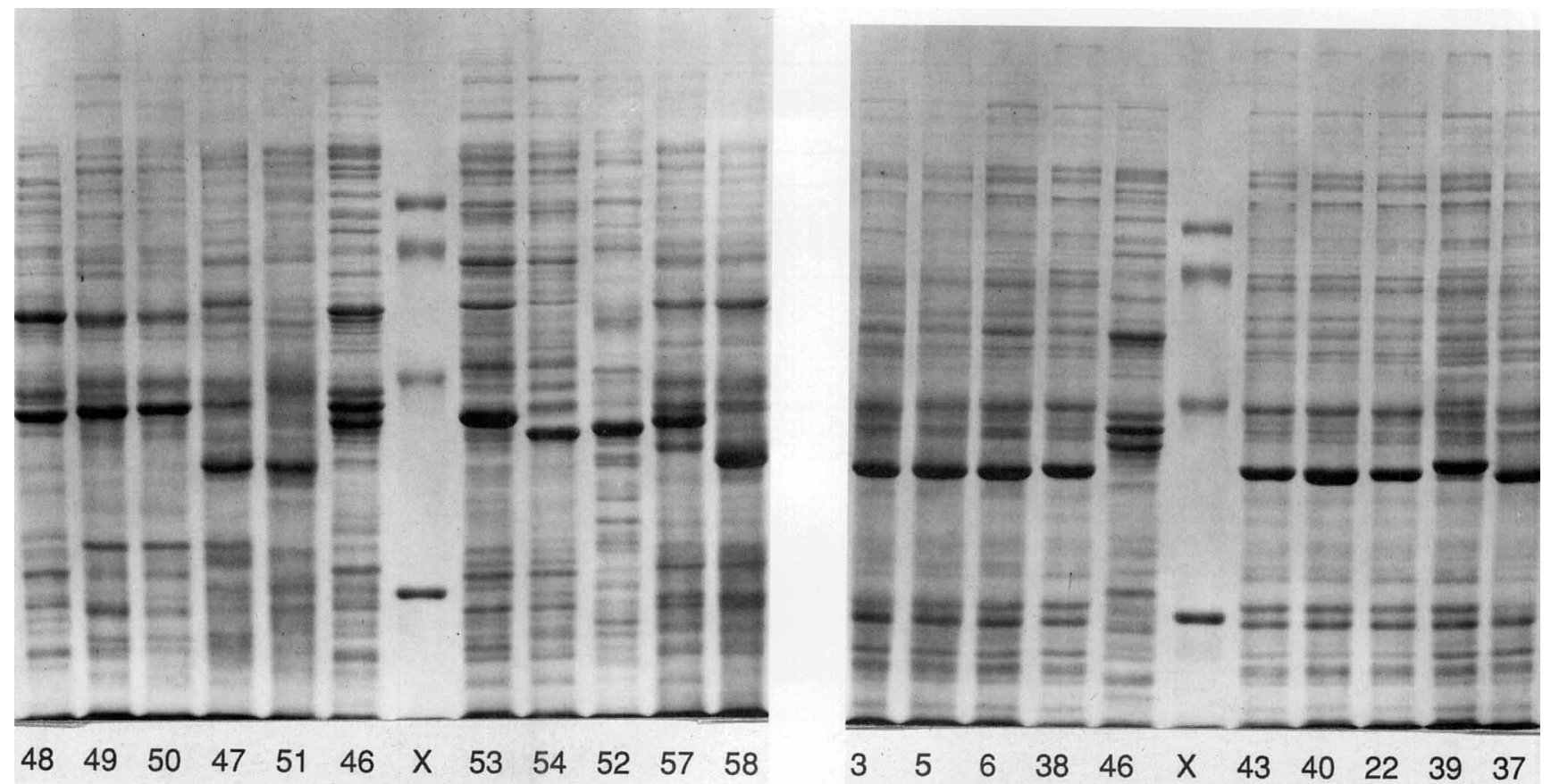

FIG. 1. Electrophoretic protein patterns of group M-5 strains and of phylogenetically closely related and phenotypically similar taxa. The lane numbers correspond to the strain reference numbers in Table 1. The molecular weights of the reference markers (lane X) were as follows (from top to bottom): ovotransferrin, 76,000 to 78,000; albumin, 66,250; ovalbumin, 42,700; and carbonic anhydrase, 30,000. The principal protein band region ( 33.0 to $46.0 \mathrm{kDa}$ ) was not used in the cluster analysis.

$(1 \%, \mathrm{wt} / \mathrm{vol})$ was determined in phenol red broth base (Difco Laboratories, Detroit, Mich.).

Preparation of protein samples, electrophoresis, staining, and scanning of gels. The methods used for protein sample preparation, electrophoresis, staining, and scanning of gels have been described elsewhere (7). The stained protein patterns in the dried gels were scanned by using the equipment and methods described previously (7), but the absorbance range used was 0.10 to 1.5 absorbance units.

Analysis and computation of similarity values. The analysis and computation of similarity values were performed as described by Costas (7) except that the protein patterns were corrected for gel-to-gel variation with a segmented linear correction by using 19 discernible marker positions on the reference pattern (the pattern of the type strain of Neisseria animalis, NCTC 10212) and a linear correction was carried out within each of the 18 defined segments for each track on the calibrated gel. The length-corrected traces on the reference gel were composed of 575 absorbance values (after removal of the initial and final bands), and the background cutoff was set at 0.4 . The best fit between each pair of traces was obtained by laterally shifting one corrected trace with respect to the other in single-point steps of $160 \mu \mathrm{m}$ up to four points on either side of the initial alignment.

The cluster analysis was based on only the partial patterns after removal of the major bands in the molecular size range from 33 to $46 \mathrm{kDa}$. It has been found in previous studies that the background (minor band) pattern offers better discrimination between species, whereas whole-cell profiles offer better discrimination between strains within a species. The partial patterns were composed of 420 absorbance values.

Preparation of high-molecular-weight DNA. High-molecular-weight native DNA was prepared as described previously (25).
DNA base compositions. All of the guanine-plus-cytosine $(\mathrm{G}+\mathrm{C})$ values were determined by the thermal denaturation method and were calculated by using the equation of Marmur and Doty (18), as modified by De Ley (9).

DNA-DNA hybridization experiments. The degree of DNADNA binding, expressed as a percentage, was determined spectrophotometrically by using the initial renaturation rate method of De Ley et al. (10). Each value given below is the average of the values from at least two hybridization experiments. DNA binding values of $30 \%$ and less do not indicate significant DNA homology. The optimal renaturation temperature in $2 \times \mathrm{SSC}(1 \times \mathrm{SSC}$ is $0.15 \mathrm{M} \mathrm{NaCl}$ plus $0.015 \mathrm{M}$ sodium citrate) was $73.3^{\circ} \mathrm{C}$.

\section{RESULTS}

A visual inspection of the whole-cell one-dimensional SDS-PAGE protein profiles showed that there were marked differences in background patterns between the M-5 strains and the strains of the other taxa examined (Fig. 1). The protein patterns were highly reproducible both within and between gels; a single protein sample from the reference strain (NCTC $10212^{\mathrm{T}}$ [T = type strain]) run on different gels gave levels of similarity of $96.7 \pm 2.1 \%$ (mean \pm standard deviation) for the seven gels examined. The levels of similarity among the strains studied (after removal of the principal bands in the 33- to $46-\mathrm{kDa}$ region) are shown in the dendrogram in Fig. 2, which was derived by using unweighted pair group linkage with mathematical averages. At a similarity level of $80 \%$ the 45 group M-5 strains formed a single cluster that was well separated from all other strains. Also at the $80 \%$ similarity level, eight individual strains or clusters were delineated which represented the various reference taxa included in the study. These clusters corre- 


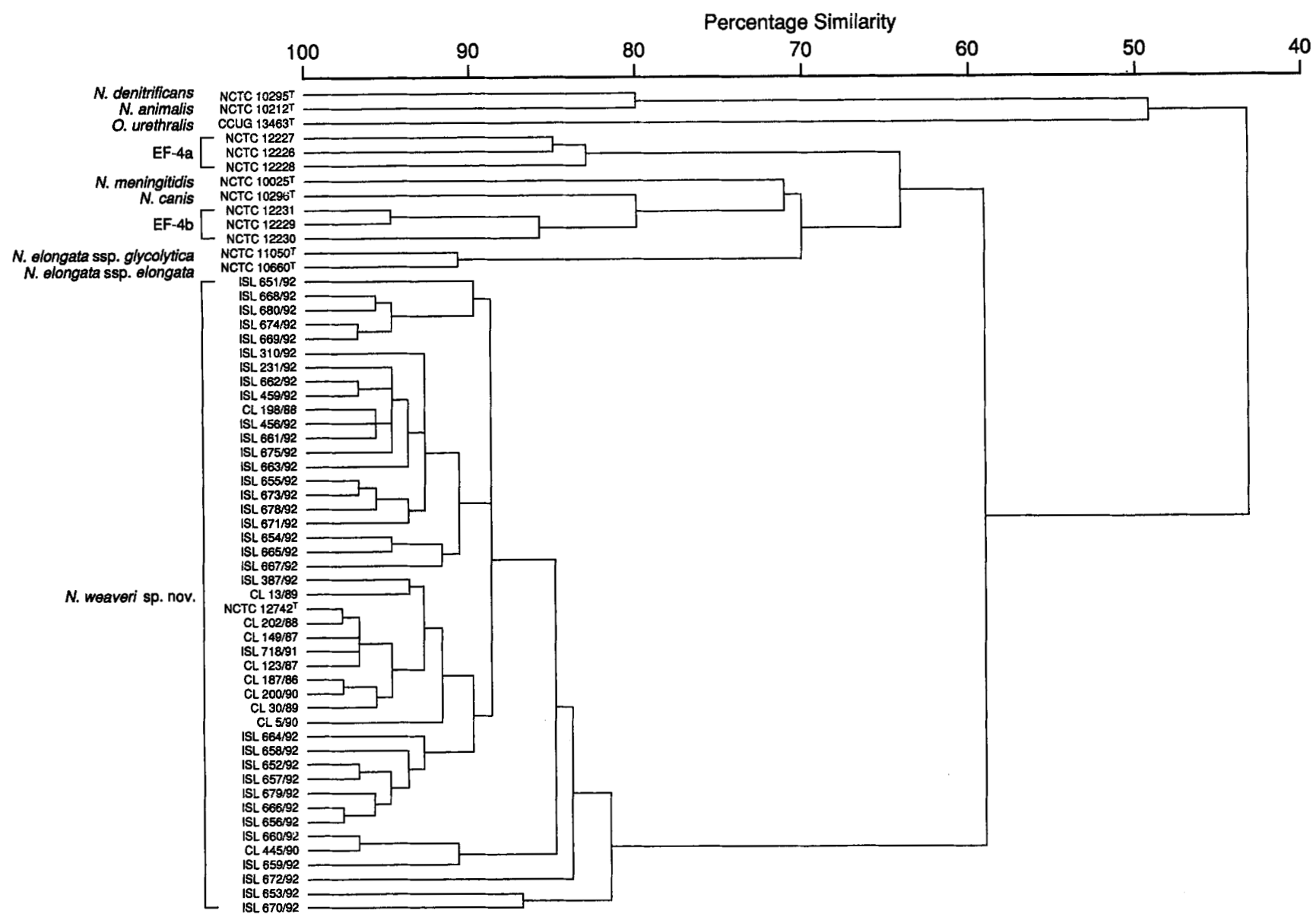

FIG. 2. Dendrogram of the cluster analysis data based on the partial protein contents of the strains listed in Table 1 (vertical axis). The values on the horizontal axis indicate the percentages of similarity as determined by the Pearson product-moment correlation coefficient and unweighted pair group average linkage clustering.

sponded to $N$. animalis, Neisseria canis, Neisseria denitrificans, Neisseria elongata subsp. elongata and $N$. elongata subsp. glycolytica (two strains), Neisseria meningitidis, $O$. urethralis, CDC group EF-4a (three strains), and CDC group EF-4b (three strains).

The $\mathrm{G}+\mathrm{C}$ contents were determined for six representative group M-5 strains (Table 2); the values determined ranged from 50 to $51 \mathrm{~mol} \%$. The results of DNA-DNA hybridization experiments are also given in Table 2, and these results show that the six strains were all highly related with DNA binding values of at least $92 \%$.

\section{DISCUSSION}

The results of this study demonstrate unequivocally that the 45 group M-5 strains examined constitute a taxon that is homogeneous with respect to phenotypic characteristics (see below), whole-cell protein patterns (Fig. 2), and, for representative strains, $\mathrm{G}+\mathrm{C}$ contents and levels of DNA-DNA hybridization (Table 2).

In a previous study of rRNA cistron similarities (22), it was proposed that the definition of the family Neisseriaceae should be emended to include the genera Alysiella,

TABLE 2. DNA base compositions and degrees of DNA relatedness of $N$. weaveri strains

\begin{tabular}{|c|c|c|c|c|c|c|c|}
\hline \multirow[b]{2}{*}{ Strain } & \multirow{2}{*}{$\begin{array}{l}\mathrm{G}+\mathrm{C} \text { content } \\
\quad(\mathrm{mol} \%)\end{array}$} & \multicolumn{6}{|c|}{$\%$ DNA binding to: } \\
\hline & & $\begin{array}{l}\text { NCTC } \\
12742^{\mathrm{T}}\end{array}$ & CL198/88 & CL123/87 & CL200/90 & CL13/89 & ISL387/92 \\
\hline NCTC $12742^{\mathrm{T}}$ & 51 & 100 & & & & & \\
\hline CL198/88 & 51 & 100 & 100 & & & & \\
\hline CL123/87 & 50 & & 100 & 100 & & & \\
\hline CL200/90 & 50 & 96 & & 99 & 100 & & \\
\hline CL13/89 & 51 & 97 & 94 & 92 & & 100 & \\
\hline ISL387/92 & 51 & & 98 & & & 96 & 100 \\
\hline
\end{tabular}


TABLE 3. Biochemical differentiation of $N$. weaveri sp. nov. from phylogenetically closely related and phenotypically similar taxa ${ }^{a}$

\begin{tabular}{|c|c|c|c|c|c|c|c|c|c|}
\hline Taxon & Catalase & Cocci & $\begin{array}{l}\text { Rods or } \\
\text { coccobacilli }\end{array}$ & Glucose & Sucrose & $\begin{array}{c}\text { Nitrate } \\
\text { reduction }\end{array}$ & $\begin{array}{c}\text { Nitrite } \\
\text { reduction }\end{array}$ & $\begin{array}{l}\text { Gas produced } \\
\text { from nitrite }\end{array}$ & $\begin{array}{l}\text { Arginine } \\
\text { dihydrolase }\end{array}$ \\
\hline N. weaveri & $+^{b}$ & - & + & - & - & - & + & - & - \\
\hline N. animalis & + & + & - & - & + & - & + & + & - \\
\hline N. canis & + & + & - & - & - & + & - & - & - \\
\hline N. denitrificans & + & + & - & + & + & - & + & + & - \\
\hline N. elongata subsp. elongata & - & - & + & - & - & - & + & + & - \\
\hline N. elongata subsp. glycolytica & + & - & + & \pm & - & - & + & - & _ \\
\hline N. elongata subsp. nitroreducens & - & - & + & - & - & + & + & - & - \\
\hline Group EF-4a & + & - & + & + & - & + & + & + & + \\
\hline Group EF-4b & + & - & + & + & - & + & + & - & - \\
\hline O. urethralis & + & + & - & - & - & - & + & + & - \\
\hline
\end{tabular}

${ }^{a}$ Data from this study. Our data for $N$. animalis agree with the data of Berger (3); our data for $N$. canis and $N$. denitrificans agree with the data of Vedros (26); our data for $N$. elongata agree with the data of Grant et al. (14) and Vedros (26); our data for groups EF-4a and EF-4b agree with the data of Holmes and Ahmed (15); and our data for $O$. urethralis agree with the data of Clark et al. (6).

$b+$, all strains tested were positive; \pm , the strain tested was weakly positive; - , all strains tested were negative.

Eikenella, and Kingella (although not Kingella indologenes), true Neisseria species (i.e., the species centered around Neisseria gonorrhoeae), other Neisseria species, the genus Simonsiella, and groups EF-4 and M-5. The other Neisseria species ( $N$. animalis, $N$. canis, $N$. denitrificans, and $N$. elongata) proved to be less closely related to the true Neisseria species, as were group EF-4a, group EF-4b, and group M-5.

Type or other reference strains of the other Neisseria species and related taxa mentioned above were included in the numerical analysis of whole-cell protein patterns obtained by SDS-PAGE. Also included was the type strain of $N$. meningitidis as a representative of the "true" neisseriae. The type strain of $O$. urethralis (also a member of rRNA superfamily III, although not a member of the Neisseriaceae) was included as phenotypically it was very similar to group M-5. The dendrogram, which was based on partial whole-cell protein patterns, demonstrated that group M-5 was clearly distinct from all of the other taxa examined. Most of the organisms included in the protein study could also be differentiated by biochemical tests, cellular morphology, or cellular fatty acid analysis (Table 3) (see below). Previously published DNA-DNA hybridization data (22) also demonstrated that group M-5 was distinct from the other Neisseria species and related taxa falling outside the true Neisseria group. The data described above unequivocally demonstrate that group M-5 represents a new species that is distinct from other members of the emended family Neisseriaceae.

The correct genus assignment for group M-5 within the Neisseriaceae is not straightforward, especially as there is no generally accepted definition of a genus in the same way that there is a generally accepted definition of a species. The previous study of rRNA cistron similarities (22) included two group M-5 strains that were also included in this study; one of these is the type strain of the new species proposed below (DNAs from both of these strains were also used in the DNA-DNA hybridization studies described in this paper). Since our group M-5 strains constitute a homogeneous taxon, any results obtained with these two strains must be representative of the taxon as a whole.

The other Neisseria species ( $N$. animalis, $N$. canis, $N$. denitrificans, and $N$. elongata) proved to be less closely related as determined by rRNA cistron similarity levels to the true Neisseria species, as were group EF-4a, group EF-4b, and group M-5. This was confirmed by DNA-DNA hybridization data, which also showed that there was no significant level of DNA homology between any pair of taxa (except between groups EF-4a and EF-4b). Of these organisms, evidence from genetic transformation studies indicated that $N$. elongata was probably a true Neisseria species, while the position of the remaining organisms was uncertain. There was insufficient evidence from rRNA cistron similarity data to warrant transferring these organisms to one or more newly created genera, and if the DNA-DNA hybridization data were used, then only groups EF-4a and EF-4b could be placed in the same genus and almost all of the other taxa would be placed in separate new genera. The latter course would unnecessarily lead to the creation of at least four monospecific genera. A comparison of 16S rRNA sequence data (10a) indicated that $N$. canis, together with CDC groups EF-4b and M-5, probably belongs with the true Neisseria species, while $N$. animalis, $N$. denitrificans, $N$. elongata subsp. elongata, and $N$. elongata subsp. nitroreducens probably do not.

The divergence level between the rRNA branches within the Neisseriaceae is situated at about $75^{\circ} \mathrm{C}$, and differences in thermal denaturation $\left[T_{m(e)}\right]$ values of about $5^{\circ} \mathrm{C}$ were measured (22). The decision whether taxa with this degree of genotypic heterogeneity should be included in a single genus depends on additional criteria, such as similarities or differences in various chemotaxonomic or other phenotypic parameters. The fatty acid profile data for the group M-5 strains essentially do not differ from the data for the group EF-4 strains and members of the genus Neisseria, especially group M-6 (the latter organism is now known as $N$. elongata subsp. nitroreducens) (14). Furthermore, the phenotypic features given below also are consistent with the generic description of the genus Neisseria. Since the 16S rRNA sequence data also indicate that group M-5 belongs with the true Neisseria species, we therefore propose that group M-5 should be elevated to the species level as a new species of the genus Neisseria.

For this new species we propose the name Neisseria weaveri (wea'ver.i. M.L. gen. n. weaveri, from Weaver, to honor R. E. Weaver, a bacteriologist at the Centers for Disease Control and Prevention in Atlanta).

Neisseria weaveri sp. nov. The characteristics of $N$. weaveri are given below. The 45 strains which we studied are strictly aerobic, gram-negative, uniformly staining, rod-shaped organisms whose cells have parallel sides and rounded ends. The cells are nonmotile in hanging-drop preparations after overnight growth in nutrient broth incubated at either $37^{\circ} \mathrm{C}$ or room temperature $\left(18\right.$ to $\left.22^{\circ} \mathrm{C}\right)$. 
TABLE 4. Characteristics in which the 45 strains of $N$. weaveri differed

\begin{tabular}{|c|c|c|c|}
\hline Characteristic & $\begin{array}{l}\text { No. of } \\
\text { strains } \\
\text { positive }\end{array}$ & $\begin{array}{l}\text { Result for } \\
\text { type strain } \\
\text { NCTC } 12742\end{array}$ & $\begin{array}{l}\text { Strain(s) that gave the less } \\
\text { common result }\end{array}$ \\
\hline Alkaline reaction in O-F test ${ }^{a}$ & 44 & + & CL5/90 \\
\hline Hemolysis & 44 & + & ISL456/92 \\
\hline Nitrite reduction & 43 & + & ISL657/92, ISL678/92 \\
\hline $\begin{array}{l}\text { Alkali production on Christensen } \\
\text { citrate }\end{array}$ & 22 & + & $\begin{array}{l}\text { CL198/88, ISL718/91, NCTC } 12742^{\mathrm{T}}\left(=\text { CCUG } 4007^{\mathrm{T}}\right) \text {, } \\
\text { ISL310/92, ISL651/92, ISL652/92, ISL653/92, ISL654/92, } \\
\text { ISL655/92, ISL656/92, ISL657/92, ISL658/92, ISL659/92, } \\
\text { ISL663/92, ISL667/92, ISL668/92, ISL669/92, ISL671/92, } \\
\text { ISL674/92, ISL675/92, ISL679/92, ISL680/92 }\end{array}$ \\
\hline $\begin{array}{l}\text { Growth in the presence of } 4 \% \\
\mathrm{NaCl}\end{array}$ & 19 & - & $\begin{array}{l}\text { CL187/86, CL149/87, CL198/88, CL13/89, CL30/89, CL445/ } \\
\text { 90, ISL718/91, ISL310/92, ISL456/92, ISL459/92, ISL654/ } \\
\text { 92, ISL655/92, ISL656/92, ISL657/92, ISL658/92, ISL659/ } \\
\text { 92, ISL661/92, ISL664/92, ISL680/92 }\end{array}$ \\
\hline Hydrolysis of Tween 20 & 15 & - & $\begin{array}{l}\text { CL445/90, ISL652/92, ISL653/92, ISL654/92, ISL658/92, } \\
\text { ISL660/92, ISL663/92, ISL665/92, ISL667/92, ISL669/92, } \\
\text { ISL670/92, ISL671/92, ISL672/92, ISL675/92, ISL678/92 }\end{array}$ \\
\hline $\begin{array}{l}\mathrm{H}_{2} \mathrm{~S} \text { production (lead acetate } \\
\text { paper method) }\end{array}$ & 2 & - & CL13/89, ISL657/92 \\
\hline Hydrolysis of tyrosine & 1 & - & CL30/89 \\
\hline
\end{tabular}

${ }^{a} \mathrm{O}-\mathrm{F}$, oxidation-fermentation.

A total of 62 characteristics are common to all strains (either all positive or all negative). There are eight characteristics in which one or more of the strains differ (Table 4). All strains are positive for the following characteristics: growth at $37^{\circ} \mathrm{C}$, growth at room temperature $\left(18\right.$ to $\left.22^{\circ} \mathrm{C}\right)$, growth on MacConkey agar, catalase production, oxidase production, and growth at $42^{\circ} \mathrm{C}$.

All strains are negative for the following characteristics: pigment production; nitrate reduction; indole production (Ehrlich reagent); growth on Simmons citrate; urease production; gelatinase production (stab and plate methods); production of $\mathrm{H}_{2} \mathrm{~S}$ in triple sugar iron agar; gluconate oxidation; malonate utilization; production of $\beta$-galactosidase; deamination of phenylalanine; arginine dihydrolase production; lysine decarboxylase and ornithine decarboxylase production; acid and gas production in glucose-peptone-water medium; production of acid from $10 \%$ (wt/vol) glucose and $10 \%$ (wt/vol) lactose; production of acid in ammonium salt medium under aerobic conditions from glucose, adonitol, arabinose, cellobiose, dulcitol, ethanol, fructose, glycerol, inositol, lactose, maltose, mannitol, raffinose, rhamnose, salicin, sorbitol, sucrose, trehalose, and xylose; production of acid in phenol red broth base under aerobic conditions from glucose and sucrose; reduction of $0.4 \%$ (wt/vol) selenite; arginine desimidase production; hydrolysis of Tween 80; production of a brown melaninlike pigment on tyrosine agar; growth on $\beta$-hydroxybutyrate (therefore there is also no accumulation of lipids after growth on this medium); esculin hydrolysis; growth on cetrimide agar; fluorescence on King medium B; growth at $5^{\circ} \mathrm{C}$; casein digestion; production of extracellular DNase; production of lecithinase; and hydrolysis of starch.

Strains contain ubiquinone with eight isoprene units as the major isoprenolog and are characterized by the presence of 3-hydroxylauric (3-OH-12:0) cellular fatty acids $(8,20)$. The $\mathrm{G}+\mathrm{C}$ contents of the DNAs of six strains of $N$. weaveri range from 50 to $51 \mathrm{~mol} \%$; the $\mathrm{G}+\mathrm{C}$ content of the DNA of the type strain is $51 \mathrm{~mol} \%$ (as estimated by the thermal denaturation method). These values agree well with those previously published for two of the strains included in this study. The type strain is NCTC 12742 (= CCUG $4007=$ ISL775/91 = LMG 5135).

$N$. weaveri strains have been isolated predominantly from the oral cavities of dogs or from human wounds following dog bites. Although this organism has been isolated from noninfected wounds by some workers (12), others have reported edema and acute pain within $24 \mathrm{~h}$ following a bite (5). Certainly, in the case described by Barnham and Holmes (2) the patient had a painful, inflamed, discharging wound within $12 \mathrm{~h}$ of being bitten. A heavy growth of the organism was obtained, and the patient made a good recovery after treatment with oral erythromycin. One of the strains used in this study, ISL718/91, was isolated from the sputum of a diabetic patient. Although it may be that the patient had a pet dog from which the isolate was acquired, it is also possible that group M-5 strains can be carried in the human oral cavity. Like several other organisms associated with dog bite wounds, group M-5 strains are susceptible to erythromycin, penicillin, and tetracycline $(5,11)$. The organism appears to be widely distributed geographically as our study (Table 1) included 20 strains from Sweden, 15 strains from the United Kingdom, 5 strains from the United States, 4 strains from France, and 1 strain from Norway.

Characteristics which differentiate $N$. weaveri from phylogenetically closely related taxa and from phenotypically similar taxa are shown in Table 3. Our phenotypic results are in close agreement with those published by other workers $(6$, $13,24)$. N. weaveri is most easily confused with $N$. elongata subsp. elongata (from which it differs in producing catalase), $N$. elongata subsp. glycolytica (from which it differs in failing to produce acid weakly from glucose), and $O$. urethralis (from which it differs in cellular morphology and cellular fatty acid composition [20]). $N$. weaveri is distinguished from typical strains of $N$. elongata subsp. nitroreducens by the ability of strains of the former to produce catalase and their failure to reduce nitrate. However, it is possible that very occasional strains of the latter taxon may produce catalase (6). Only recently described (so not included in Table 3 ) is Gilardi rod group 1 . This organism is phenotypically most similar to $N$. weaveri but differs in 
failing to reduce nitrite; its cellular fatty acid profile is also quite distinct from that of $N$. weaveri (19).

The protein data also confirmed previous findings (16) by dividing group EF-4 strains into two distinct phena.

\section{ACKNOWLEDGMENTS}

We thank the Department of Medical Illustration at the Central Public Health Laboratory, London, for assistance in production of the figures.

P.V. is indebted to the National Fund for Scientific Research (Belgium) for a position as a postdoctoral researcher. K.K. is indebted to the Fund for Medical Scientific Research, Belgium, for research and personnel grants.

\section{REFERENCES}

1. Bailie, W. E., E. C. Stowe, and A. M. Schmitt. 1978. Aerobic bacterial flora of oral and nasal fluids of canines with reference to bacteria associated with bites. J. Clin. Microbiol. 7:223-231.

2. Barnham, M., and B. Holmes. 1992. Isolation of CDC group M-5 and Staphylococcus intermedius from infected dog bites. J. Infect. 25:332-334.

3. Berger, U. 1960. Neisseria animalis nov. spec. Z. Hyg. Infektionskr. 147:158-161.

4. Brook, I. 1989. Human and animal bite infections. J. Fam. Pract. 28:713-718.

5. Canton, P., T. May, J. Burdin, and C. Lion. 1987. Pasteurellosis and bacteria EF4, M5 and IIJ: pathogenic role in man following animal bites and bacterial sensitivity. Chemiotherapia 6(Suppl. 2):26-28.

6. Clark, W. A., D. G. Hollis, R. E. Weaver, and P. Riley. 1984. Identification of unusual pathogenic gram-negative aerobic and facultatively anaerobic bacteria, p. 190-191. Centers for Disease Control, Atlanta.

7. Costas, M. 1992. Classification, identification and typing of bacteria by the analysis of their one-dimensional polyacrylamide gel electrophoretic protein patterns, p. 351-408. In A. Chrambach, M. J. Dunn, and B. J. Radola (ed.), Advances in electrophoresis, vol. 5. VCH Verlagsgesellschaft $\mathrm{mbH}$, Weinheim, Germany.

8. Dees, S. B., J. Powell, C. W. Moss, D. G. Hollis, and R. E. Weaver. 1981. Cellular fatty acid composition of organisms frequently associated with human infections resulting from dog bites: Pasteurella multocida and groups EF-4, IIj, M-5, and DF-2. J. Clin. Microbiol. 14:612-616.

9. De Ley, J. 1970. Reexamination of the association between melting point, buoyant density, and chemical base composition of deoxyribonucleic acid. J. Bacteriol. 101:738-754.

10. De Ley, J., H. Cattoir, and A. Reynaerts. 1970. The quantitative measurement of DNA hybridization from renaturation rates. Eur. J. Biochem. 12:133-142.

10a.Dewhirst, F. E., and B. J. Paster. Personal communication.

11. Goldstein, E. J. C., and D. M. Citron. 1988. Comparative activities of cefuroxime, amoxicillin-clavulanic acid, ciprofloxacin, enoxacin, and ofloxacin against aerobic and anaerobic bacteria isolated from bite wounds. Antimicrob. Agents Chemother. 32:1143-1148.

12. Goldstein, E. J. C., D. M. Citron, B. Wield, U. Blachman, V. L. Sutter, T. A. Miller, and S. M. Finegold. 1978. Bacteriology of human and animal bite wounds. J. Clin. Microbiol. 8:667-672.

13. Graham, D. R., J. D. Band, C. Thornsberry, D. G. Hollis, and
R. E. Weaver. 1990. Infections caused by Moraxella, Moraxella urethralis, Moraxella-like groups M-5 and M-6, and Kingella kingae in the United States, 1953-1980. Rev. Infect. Dis. 12:423-431.

14. Grant, P. E., D. J. Brenner, A. G. Steigerwalt, D. G. Hollis, and R. E. Weaver. 1990. Neisseria elongata subsp. nitroreducens subsp. nov., formerly CDC group M-6, a gram-negative bacterium associated with endocarditis. J. Clin. Microbiol. 28:25912596.

15. Holmes, B., and M. S. Ahmed. 1981. Group EF-4: a Pasteurellalike organism, p. 161-174. In M. Kilian, W. Frederiksen, and E. L. Biberstein (ed.), Haemophilus, Pasteurella and Actinobacillus. Academic Press, London.

16. Holmes, B., M. Costas, and A. C. Wood. 1990. Numerical analysis of electrophoretic protein patterns of group EF-4 bacteria, predominantly from dog-bite wounds of humans. $J$. Appl. Bacteriol. 68:81-91.

17. Holmes, B., S. P. Lapage, and H. Malnick. 1975. Strains of Pseudomonas putrefaciens from clinical material. J. Clin. Pathol. 28:149-155.

18. Marmur, J., and P. Doty. 1962. Determination of the base composition of deoxyribonucleic acid from its thermal denaturation temperature. J. Mol. Biol. 5:109-118.

19. Moss, C. W., M. I. Daneshvar, and D. G. Hollis. 1993. Biochemical characteristics and fatty acid composition of Gilardi rod group 1 bacteria. J. Clin. Microbiol. 31:689-691.

20. Moss, C. W., P. L. Wallace, D. G. Hollis, and R. E. Weaver. 1988. Cultural and chemical characterization of CDC groups EO-2, M-5, and M-6, Moraxella (Moraxella) species, Oligella urethralis, Acinetobacter species, and Psychrobacter immobilis. J. Clin. Microbiol. 26:484-492.

21. Phillips, G., D. Patterson, P. Montieth, and H. Malnick. 1991. Septicaemia caused by a penicillin-resistant Moraxella-like organism in a neutropenic patient. Eur. J. Clin. Microbiol. Infect. Dis. 10:947-948.

22. Rossau, R., G. Vandenbussche, S. Thielemans, P. Segers, H. Grosch, E. Göthe, W. Mannheim, and J. De Ley. 1989. Ribosomal ribonucleic acid cistron similarities and deoxyribonucleic acid homologies of Neisseria, Kingella, Eikenella, Simonsiella, Alysiella, and Centers for Disease Control groups EF-4 and M-5 in the emended family Neisseriaceae. Int. J. Syst. Bacteriol. 39:185-198.

23. Saphir, D. A., and G. R. Carter. 1976. Gingival fiora of the dog with special reference to bacteria associated with bites. J. Clin. Microbiol. 3:344-349.

24. Tatum, H. W., W. H. Ewing, and R. E. Weaver. 1974. Miscellaneous Gram-negative bacteria, p. 270-294. In E. H. Lennette, E. H. Spaulding, and J. P. Truant (ed.), Manual of clinical microbiology, 2nd ed. American Society for Microbiology, Washington, D.C.

25. Vandamme, P., M. Vancanneyt, B. Pot, L. Mels, B. Hoste, D. Dewettinck, L. Vlaes, C. Van Den Borre, R. Higgins, J. Hommez, K. Kersters, J.-P. Butzler, and H. Goosens. 1992. Polyphasic taxonomic study of the emended genus Arcobacter with Arcobacter butzleri comb. nov. and Arcobacter skirrowii sp. nov., an aerotolerant bacterium isolated from veterinary specimens. Int. J. Syst. Bacteriol. 42:344-356.

26. Vedros, N. A. 1984. Genus I. Neisseria Trevisan $1885,105^{\mathrm{AL}}$, p. 290-296. In N. R. Krieg and J. G. Holt (ed.), Bergey's manual of systematic bacteriology, vol. 1. The Williams \& Wilkins Co., Baltimore. 